\title{
"De que lado estás, Ariel?": reconhecimento e redistribuição na teoria da emancipação de Boaventura de Sousa Santos ${ }^{1}$
}

Josué Pereira da Silva ${ }^{2}$

\section{Resumo}

O artigo lida com a abordagem de Boaventura de Souza Santos a respeito do debate entre reconhecimento e redistribuição. Tendo em vista a ideia de Nuestra América, do cubano José Martí e a metáfora shakespeariana de Ariel, Santos elabora o que denomina paradigma subalterno de reconhecimento (diferença) e redistribuição (igualdade), fundado em uma epistemologia do sul que ele contrapõe ao chamado paradigma americano-europeu, cuja expressão é a globalização neoliberal. Ele argumenta, então, que é preciso enfrentar esse paradigma da globalização dominante com um paradigma contra-hegemônico de globalização.

Palavras-chave: Reconhecimento. Redistribuição. Epistemologia do Sul. Nuestra América. Boaventura de Sousa Santos.

\section{Introdução}

Desde 1995, o recente debate sobre reconhecimento, desencadeado alguns anos antes pelos trabalhos de Charles Taylor e de Axel Honneth, ganhou nova feição, com a introdução nele, por Nancy Fraser, do tema

\footnotetext{
I A parte entre aspas do título deste artigo é uma expressão utilizada por Boaventura de Sousa Santos como subtítulo da conclusão de seu texto "Nuestra América: reinventar um paradigma subalterno de reconhecimento e redistribuição" (SANTOS, 2006a, p. 223).

2 Josué Pereira da Silva é Professor de Sociologia no Instituto de Filosofia e Ciências Humanas (IFCH), da Universidade Estadual de Campinas (UNICAMP). E-mail: josueps@unicamp.br
}

\section{$(\infty))$ EY}

Direito autoral e licença de uso: Este artigo está licenciado sob uma Licença Creative Commons. Com essa licença você pode compartilhar, adaptar, para qualquer fim, desde que atribua a autoria da obra, forneça um link para a licença, e indicar se foram feitas alterações. 
da redistribuição (FRASER, 1995). Com isso, muitos autores que antes se limitavam a discutir problemas de reconhecimento tiveram de considerar em suas formulaçóes também problemas de redistribuição. Enquanto os debates sobre reconhecimento decorriam de preocupaçôes com problemas de identidade e diferença, a introduçáo no debate do tema da redistribuição remetia, sobretudo, ao problema da igualdade social. Na verdade, a entrada de Fraser no debate, em 1995, teve justamente a intenção de alertar para os limites das políticas de identidade e para o abandono por setores dos movimentos sociais da luta por igualdade social, tema que por muito tempo foi central para as pautas da Esquerda, velha e nova. ${ }^{3}$

Assim, o problema da relação entre reconhecimento e redistribuição acabou por protagonizar um dos debates mais importantes em teoria social crítica na última década do Século XX e na primeira do Século XXI, resultando com isso em uma extensa bibliografia, cuja principal referência ainda é o livro Recognition or redistribution? A political-philosophical exchange (FRASER; HONNETH, 2003), no qual Fraser e Honneth dialogam criticamente e apresentam suas respectivas formulaçóes sobre o tema.

Minha intenção neste artigo, porém, não é reproduzir esse debate, sobre o qual, aliás, já escrevi alhures. ${ }^{4}$ Meu objetivo aqui é bem mais restrito e se limita a abordar a contribuiçáo de Boaventura de Sousa Santos para o mesmo debate, a partir de uma perspectiva - teorias do sul - pouco contemplada até aqui pela bibliografia pertinente. Sua formulação a respeito do tema, a partir da perspectiva de uma epistemologia do sul, é bastante peculiar e coloca desafios que não se encontram, ao menos explicitamente, nas contribuiçóes de outros protagonistas do debate. É essa peculiaridade, a meu ver, que justifica um texto lidando especificamente com sua contribuição ao tema, explorando-a mais a fundo. Ainda que a menção a reconhecimento e redistribuição apareça em muitos textos de Boaventura de Sousa Santos, é em seu "Nuestra América: reinventar um paradigma subalterno de reconhecimento e redistribuição" (SANTOS, 2001, 2006a), que ele aborda mais diretamente o problema da relação entre os dois temas. Por isso, embora eu recorra a outros textos de sua autoria, esse último será meu ponto de partida.

3 Escrevi recentemente sobre as pautas de esquerda em texto ainda não publicado (SILVA, 20I8b).

4 Ver, a propósito, Silva, 2008c, p. 93-110; 2009, p. 196-205; 2014, p. 1/9-145. Para um balanço da recepção no Brasil, desses debates ver: Souza, 2012. 
Da mesma forma como fazem Axel Honneth e Nancy Fraser, Boaventura de Sousa Santos também reivindica para sua formulação o status de teoria crítica. Ele considera, aliás, que Max Horkheimer é o autor que melhor definiu teoria crítica (SANTOS, 2000, p. 23-37; SILVA, 2018a), embora veja nela sérios limites, que em seu entendimento não são apenas da formulação de Horkheimer. Para Santos, na verdade, as teorias críticas desde Marx - passando pelos autores da chamada Escola de Frankfurt, além de partilharem o mesmo paradigma da modernidade - assentam-se em pressupostos eurocêntricos que as deixam cegas em relação ao que acontece no restante do mundo. Esses são dois limites que Santos ambiciona ultrapassar com sua teoria da emancipaçáo; para tanto, esta última se apresenta ao mesmo tempo como uma teoria crítica pós-moderna e, principalmente, como uma epistemologia do sul.

Nas páginas a seguir, desenvolvo meu argumento em três partes. Começo introduzindo sua abordagem a respeito de "um paradigma subalterno de reconhecimento e redistribuição", baseada na ideia de Nuestra América, do cubano José Martí, que Santos contrapóe ao que ele denomina paradigma americano-europeu (item I). Se, para Santos, este último se caracteriza pela atual hegemonia do pensamento abissal (ciência dominante) e da globalização neoliberal, é preciso, então, opor-se a ele por meio de um paradigma contra-hegemônico, definido como epistemologia do sul, que será a base teórica do projeto de uma globalização contra-hegemônica capaz de enfrentar o neoliberalismo dominante (item II). À luz desta epistemologia do sul, retorno à sua análise dos temas do reconhecimento (diferença) e da redistribuição (igualdade), tendo em vista suas proposições - novos manifestos de políticas orientadas para a emancipação e também ao papel de mediador que ele atribui à figura metafórica de Ariel na luta por emancipação (item III). E, por fim, faço minhas consideraçóes críticas sobre a abordagem de Santos, comparando-a também com as proposiçôes de Axel Honneth e de Nancy Fraser a respeito do debate reconhecimento/redistribuiçáo.

\section{I}

Santos inicia seu texto sobre reconhecimento e redistribuição, descrevendo o que denomina século americano-europeu, para o que ele faz referência à tese de Friedrich Hegel, segundo a qual "a história universal 
desloca-se do Oriente para o Ocidente", de forma que o processo civilizatório tem início na Ásia e completa-se na Europa, onde se consumaria "a trajetória civilizacional da humanidade". ${ }^{5}$ Assim, segundo Santos,

A ideia bíblica e medieval da sucessão dos impérios (translatio imperii) transforma-se, em Hegel, no percurso triunfante da 'Ideia Universal'. Em cada era, um povo assume a responsabilidade de conduzir a Ideia Universal, tornando-se, assim, o povo histórico universal, privilégio que passou sucessivamente dos asiáticos para os gregos, depois para os romanos e, finalmente, para os povos germânicos. Para Hegel, a América, ou antes, a América do Norte, transporta um futuro ambíguo, na medida em que não colide com a realização absoluta da história universal na Europa [...]. O futuro da América (do Norte) é ainda um futuro europeu, formado pelos restos da população europeia. (SANTOS, 2006a, p. 191).

Ainda segundo Santos, essa formulação hegeliana "subjaz à concepção do século XX como o 'Século Americano': o Século Americano-Europeu”. Neste último, para ele,

[...] está contida a noção de que a americanização do mundo, iniciada com a americanização da própria Europa, não é senão um efeito da astúcia universal da razão, a qual, tendo atingido o extremo do Ocidente e mostrando-se irreconciliada com o exílio a que Hegel a condenou, foi forçada a voltar atrás, a percorrer de novo o seu trajeto anterior e, uma vez mais, a traçar o caminho para a sua hegemonia sobre o Oriente. A americanização, enquanto forma hegemônica da globalização, é, pois, o terceiro ato do drama milenar da supremacia ocidental. (SANTOS, 2006a, p. 191). ${ }^{6}$

Para Santos (2006a, p. 192), este terceiro ato - denominado Século Americano-Europeu - "[...] acarretou pouca novidade: nada mais foi que mais um Século Europeu, o último do milênio". Ressalta, ainda, que "a Europa sempre conteve muitas europas, umas dominantes, outras dominadas”; assim, acrescenta ele, "[...] os Estados Unidos da América são a última Europa dominante e, como as outras, exerce o seu poder incontestado sobre as europas dominadas" (SANTOS, 2006a, p. 192).

Embora reconheça a dificuldade neste momento histórico de se construir uma alternativa ao capitalismo global, liderado pelos EUA, Santos (2006a, p. 192) argumenta que "uma tal alternativa é não só necessária mas urgente". Afinal, ele enfatiza,

5 Para conferir, ver Hegel, 1956. Para uma crítica de Hegel próxima à de Santos, ver Buck-Morss, 2009.

6 Ele diz também que as cruzadas consistiram no primeiro ato, enquanto o segundo foi a expansão europeia. 
[...] o regime de dominação global actual ${ }^{7}$, à medida que perde coerência, mostra-se cada vez mais violento e imprevisível, aumentando desse modo a vulnerabilidade das regiões, das nações e dos grupos sociais subordinados e oprimidos. O perigo real, tanto nas relações internas dos países que compõem o sistema mundial, como nas relações internacionais, é a emergência daquilo a que chamo fascismo social. (SANTOS, 2006a, p. 192). ${ }^{8}$

Para Santos, há muitos sinais de que a expansão do fascismo social é uma possibilidade real, um futuro previsível. Em suas palavras:

Se se permitir que a lógica do mercado transborde da economia para todas as áreas da vida social e se torne o único critério para a interacção social e política de sucesso, a sociedade tornar-se-á ingovernável e eticamente repugnante, e, seja qual for a ordem que se venha a efectivar, ela será de tipo fascista. (SANTOS, 2006a, p. 193).

Por isso, ele defende, como alternativa ao fascismo social, "[...] a construçáo de um novo padráo de relaçóes locais, nacionais e internacionais, baseadas simultaneamente no princípio da redistribuição (igualdade) e no princípio do reconhecimento (diferença)" (SANTOS, 2006a, p. 193). Tais relaçôes, segundo Santos, devem emergir como globalizaçóes contra-hegemônicas. Assim, enquanto a globalização neoliberal hegemônica expressa a dominação do Século Americano-Europeu, as globalizaçóes contra-hegemônicas expressam o potencial emancipatório das lutas contra o capitalismo neoliberal travadas nas margens deste último; é daí, segundo Santos, que pode emergir outro Século Americano. Desta vez, porém, assentado na ideia de Nuestra América.

Conforme já dito antes, Santos apoia-se para tanto nas ideias do cubano José Martí, contidas no texto "Nuestra América”, de 1891.9 Segundo Santos, "[...] neste artigo, um excelente resumo do pensamento do autor que se encontra disperso em diversos jornais latino-americanos da época, Martí exprime o conjunto de ideias que creio presidirem ao Século Americano Nuestra América" (SANTOS, 2006a, p. 199).

\footnotetext{
7 Os trechos citados de obras com grafia de Português de Portugal, publicados anteriormente ao novo acordo ortográfico, foram mantidos sem correções neste artigo.

8 Embora considere que o fascismo social seja pluralista, Santos o define como "[...] um conjunto de processos sociais mediante os quais grandes sectores da população são irremediavelmente mantidos no exterior ou expulsos de qualquer tipo de contrato social" (SANTOS, 2006a, p. 192).

9 Ver Martí (2005)
} 
Trata-se, segundo Santos, de um conjunto formado por cinco ideias principais, conforme ele as delineia a seguir. A primeira delas

[...] é que a Nuestra América está nos antípodas da América Europeia. É a América mestiça fundada no cruzamento, tantas vezes violento, de muito sangue europeu, índio e africano. É a América capaz de sondar profundamente as suas próprias raízes e de, nessa base, edificar um conhecimento e uma forma de governo que não sejam importados, mas antes adequados à sua realidade. As suas raízes mais profundas estão na luta dos povos ameríndios contra os seus invasores. (SANTOS, 2006a, p. 200).

Santos afirma ainda que embora nesse texto Martí fale apenas do racismo anti-índio; em outros textos, ele se refere ao racismo contra os negros.

A segunda ideia de Nuestra América, apontada por Santos, é que "[...] nas suas raízes mistas reside a sua complexidade infinita, sua forma de universalismo que enriqueceu o mundo"; e, para tanto, ele cita Martí: "Náo há ódio racial, porque não há raças” (2005 apud SANTOS, 2006a, p. 200). Para Santos, esse "tipo de universalismo situado e contextualizado", também presente, por exemplo, na antropofagia de Oswald de Andrade, na transculturação de Fernando Ortiz e na mestiçagem de Darcy Ribeiro, "iria tornar-se um dos fios condutores mais consistentes de Nuestra América” (SANTOS, 2006a, p. 200). ${ }^{10}$

De acordo com a terceira ideia fundadora, Nuestra América tem que se dotar de um conhecimento genuíno. Para que isso ocorra, afirma Santos, "as ideias têm de ser enraizadas nas aspiraçóes dos povos oprimidos", e para tanto cita Martí:

[...] universidade europeia tem de ceder à universidade americana. A história da América, desde os Incas até ao presente, deve ser ensinada na perfeição, ainda que não se ensine a dos arcontes da Grécia. A nossa Grécia é preferível à Grécia que não é nossa. É-nos mais necessária. Os políticos exóticos hão-de ser substituídos pelos políticos nacionais. Enxerte-se o mundo nas nossas repúblicas, mas o tronco há-de ser das nossas repúblicas. E que o pedante vencido se cale, pois não há pátria de que o homem possa ter mais orgulho do que as nossas dolorosas repúblicas americanas. (1963 apud SANTOS, 2006a, p. 201).

10 Ora, se Santos insiste, citando Martí, que "não há raças", por que então recorrer à ideia de "mestiçagem" que é um subproduto da concepção racialista criticada por Martí. Aliás, vale lembrar aqui que embora Santos não mencione o Gilberto Freyre de Casa Grande e Senzala, há claras semelhanças entre sua abordagem sobre o tema e as formulações do sociólogo brasileiro (FREYRE, 1980). Todas as ênfases em negrito usadas neste artigo são minhas. 
Para Santos, o "conhecimento genuíno" que se pode discernir na tese de Martí, "[...] é o que verdadeiramente distingue um país, e não a atribuição imperial de níveis de civilização", acrescentando que, com base nessa ideia, "[...] Martí estabelece uma distinção entre o intelectual e o homem que a experiência vivida tornou sensato" (SANTOS, 2006a, p. 201). Assim, para Santos, Nuestra América tem "uma forte componente epistemológica”, que supõe "um conhecimento situado" como "a condição para um governo situado"; ou, nas palavras do próprio José Martí, "os governadores, na república dos índios, aprendem índio” (1963 apud SANTOS, 2006a, p. 202).

A quarta ideia fundadora faz referência direta à metáfora shakespeariana da peça $A$ tempestade." Ou seja, conforme Santos, "Nuestra América é a América de Caliban, e não a de Próspero". Isto porque para Martí, acrescenta Santos (2006a, p. 202), “[...] a América de Próspero reside no Norte, mas também subsiste no Sul através dessas elites intelectuais e políticas que rejeitam as raízes índias e negras, encarando a Europa e os Estados Unidos da América como modelos a imitar, e encarando seus próprios países com antolhos etnocêntricos".

Aqui, a despeito da crítica de Santos a Hegel, cabe uma referência a esse último. A meu ver, a metáfora shakespeareana nos faz lembrar outra metáfora de Hegel, igualmente famosa: a da dialética do senhor e do escravo (HEGEL, 1977). Assim, à dupla shakespeareana Próspero/Caliban corresponde o par Senhor/Escravo de Hegel; mas, enquanto no primeiro caso é Ariel que faz a mediação entre Próspero e Caliban, na metáfora hegeliana a mediação na relação Senhor/Escravo é feita pelo trabalho. Ou seja, uma mediação é metafórica, mas a outra é bastante real. ${ }^{12}$

Por fim, a quinta ideia de Nuestra América é que, segundo Santos, o pensamento político dela "longe de ser nacionalista, é internacionalista e reforçado por uma atitude anticolonialista e anti-imperialista" (SANTOS, 2006a, p. 202). Aqui Santos chama a atenção para o que Martí escreve

11 Ver Shakespeare (1964).

12 Vale também conferir a crítica de Susan Buck-Morss (2009) à metáfora de Hegel, que para ela deve se remeter obrigatoriamente à revolução do Haiti, um acontecimento que os estudiosos de Hegel geralmente ignoram. 
sobre os Estados Unidos da América. Tendo vivido lá durante seus muitos anos de exílio, Martí estava, segundo Santos, "familiarizado com 'as entranhas do monstro", conforme fica claro no texto do cubano citado a seguir:

[...] No Norte não há amparo nem raiz. No Norte os problemas agravam-se, e não existe a caridade e o patriotismo que poderiam resolver. Aqui, os homens não aprendem a amar-se, nem amam o solo onde nascem por acaso, e onde brigam sem tréguas na luta, animal e atribulada, pela existência. Aqui, montou-se uma máquina mais esfomeada do que a que pode satisfazer o universo necessitado de produtos. Aqui, repartiu-se mal a terra, e a produção, desigual e monstruosa, e a inércia do solo apropriado deixam o país sem a salvaguarda do cultivo distribuído, que dá de comer quando não dá para ganhar. Aqui, os ricos amontoam-se de um lado, e os desesperados do outro. O Norte fecha-se e está cheio de ódios. É preciso ir saindo do Norte. (MARTÍ, 1963 apud SANTOS, 2006a, p. 203).

Alertando para os riscos "de Nuestra América e da América Europeia estarem geograficamente tão próximas”, Santos afirma, em linha com Martí, que a "alternativa reside em uma Nuestra América unida e na afirmação da sua autonomia face aos EUA" (SANTOS, 2006a, p. 203). Sendo este último país o principal representante da globalização neoliberal, Santos afirma, seguindo Martí, que a autonomia de Nuestra América remete necessariamente às lutas por outro tipo de globalização, definida aqui como contra-hegemônica. ${ }^{13}$

Santos define a "[...] globalização hegemônica como o processo através do qual um dado fenômeno ou entidade local consegue difundir-se globalmente e, ao fazê-lo, adquire a capacidade de designar um fenômeno ou entidade rival como local". Por isso, em seu entendimento, primeiramente, "não há uma globalização genuína" e, em segundo lugar, "a globalização envolve localização, isto é, a localização dos vencidos”; ou seja, ela é simultaneamente localismo globalizado e globalismo localizado. Por essa mesma razão, ele afirma também que seria analiticamente correto definir "a situação actual [...] em termos de localização, em vez de globalização" (SANTOS, 2006a, p. 195).

13 Santos escreve que, para Martí, "[...] a reivindicação da igualdade fundamenta a luta contra a diferença desigual, tanto quanto a reivindicação da diferença fundamenta a luta contra a igualdade desigual"; para tanto, ele (Santos) recorre também à antropofagia de Oswald de Andrade, acrescentando que "[...] a única canibalização legítima da diferença [...] é a que o subalterno pratica, pois só através dela Caliban consegue reconhecer a sua própria diferença face às diferenças desiguais que lhe são impostas" (SANTOS, 2006a, p. 204). 
Ao desenvolver sua análise dos atuais processos de globalização, Santos (2011) fala em quatro modos de produção da globalização, descritas como econômica, social, política e cultural. E para especificar cada um deles, ele remete a globalização econômica à expansão do neoliberalismo, vinculando-a ao que considera os três grandes capitalismos atuais: norte-americano, europeu e japonês. ${ }^{14}$ A globalização social, o segundo modo a que ele se refere, está associada ao crescimento exponencial das desigualdades sociais que decorre da própria expansão do neoliberalismo. Resulta também da expansão deste último a globalização política, identificada por ele com o declínio do Estado-nação. Já a globalização cultural caracteriza-se, segundo Santos, pela expansáo da cultura global dos países do centro para as mais diversas partes do mundo. Os quatro tipos acima fazem parte de um mesmo processo mais amplo, no qual, sob a hegemonia da globalização econômica neoliberal, todos estão intimamente relacionados.

Entretanto, para "dar conta das relaçôes de poder assimétricas no interior do que chamamos globalização", ele sugere outra "[...] distinção entre quatro modos de produção da globalização: localismos globalizados, globalismos localizados, cosmopolitismo e patrimônio comum da humanidade" (SANTOS, 2006a, p. 195). Desta última tipologia, ele deriva as duas formas de globalização, definidas como hegemônica e contra-hegemônica, às quais ele associa, respectivamente, de um lado, os localismos globalizados e os globalismos localizados, e, de outro, o cosmopolitismo e o patrimônio comum da humanidade (SANTOS, 2006a, 2011).

Segundo a formulaçáo de Boaventura de Sousa Santos, o fundamento teórico das lutas por emancipação relacionadas à globalização contra-hegemônica deve ser buscado nas abordagens denominadas epistemologias do sul. Por isso, meu próximo passo é mostrar sua versão desta última; ou seja, sua teoria da emancipaçáo (SILVA, 2018a).

\section{II}

A teoria da emancipação de Boaventura de Sousa Santos, conforme ele mesmo indica, compóe-se de três procedimentos, definidos como

14 Santos não faz aqui qualquer referência ao capitalismo chinês, que nos últimos anos se tornou um dos principais atores da economia mundial. 
sociologia das ausências, sociologia das emergências e trabalho de tradução. Estes três procedimentos, dos quais falarei mais detidamente a seguir, constituem a base de sua epistemologia do sul, que ele apresenta como uma teoria alternativa - em alguns momentos nomeada como ecologia dos saberes - que se contrapóe ao denominado pensamento abissal das teorias eurocêntricas (SANTOS, 2010a, 2010b).

O principal ponto de partida de Santos na elaboração de sua teoria é o que ele denomina crítica da razão indolente, tema ao qual ele dedica um de seus principais livros (SANTOS, 2000). A razão indolente, à qual ele contrapóe sua epistemologia do sul, caracteriza-se pelo que ele chama de desperdício de experiência e se manifesta de duas formas principais: como razão metonímica e como razão proléptica. É a partir da crítica a essas duas formas de razão que ele desenvolve, como contraponto, a sociologia das ausências e a sociologia das emergências, completadas posteriormente pelo trabalho de tradução. Porém, antes de analisar especificamente sobre o que ele denomina como três procedimentos, é preciso apresentar sua definição da razão indolente, em seus respectivos desdobramentos.

Conforme dito antes, para Santos, a razão indolente se caracteriza pelo desperdício de experiência, que se manifesta como uma razão metonímica, que contrai o presente, e como uma razão proléptica, que expande o futuro. Segundo Santos, para contrair o presente, a razáo metonímica toma a parte pelo todo, utilizando um conceito restrito de totalidade construído de partes homogêneas. Um dos principais aspectos desse procedimento de tomar a parte pelo todo é o desperdício de experiências; ou seja, ao contrair, diminuir, subtrair o presente, a razão metonímica deixa fora muita realidade e muita experiência que são, assim, tornadas invisíveis. A razão proléptica, por sua vez, é aquela que expande o futuro. Essa expansão do futuro funda-se em uma concepçáo de tempo linear, que incorpora uma noção de progresso e uma ideia de desenvolvimento, sobretudo econômico, que expande o futuro, tornando-o infinito. Ao assim fazer, a razão proléptica elimina ou marginaliza outras concepçóes de tempo, outros modos de ver o progresso e o desenvolvimento, deixando de fora com isso também outros modos de vida que não os consagrados pela visão eurocêntrica de mundo (SANTOS, 2006b, 2007). 
Ao desconsiderar a heterogeneidade do mundo, a razão indolente contribui, portanto, para desperdiçar outras experiências que não as europeias e se torna o principal fundamento do pensamento abissal, nome que Santos dá à ciência moderna, a qual desqualifica outras formas de saber e de conhecimento que não ela própria, praticando, assim, o que ele chama de epistemicídio (SANTOS, 1987, 2000, 2007).

Por isso, sua epistemologia do sul, que emerge em contraposição à ciência dominante, apoia-se no seguinte princípio fundamental: não há justiça social global sem justiça cognitiva global; isto é, sem justiça entre os conhecimentos. Ademais, ele acrescenta, a diversidade do mundo é inesgotável, por isto não há teoria geral que possa organizar toda essa heterogeneidade. Mas se "[...] não há cultura que seja completa, é então preciso fazer tradução para ver a diversidade sem relativismo, porque os que estamos comprometidos com as mudanças sociais não podemos ser relativistas" (SANTOS, 2007, p. 41). Daí surge o trabalho de tradução, o terceiro procedimento necessário para completar, junto com a sociologia das ausências e a sociologia das emergências, a teoria da emancipação. Por outro lado, embora sustente que não há teoria geral capaz de fazer justiça à diversidade do mundo, ele afirma que ainda assim "necessitamos de uma teoria geral sobre a impossibilidade de uma teoria geral" (SANTOS, 2007, p. 39).

Partindo do princípio fundamental referido acima, Santos apresenta, em contraposição respectivamente à razão metonímica e à razão proléptica, uma sociologia das ausências e uma sociologia das emergências, definidas por ele a seguir. A sociologia das ausências é definida, portanto, como

[...] uma investigação que visa a demonstrar que o que não existe é, na verdade, activamente produzido como não existente, isto é, como uma alternativa não credível ao que existe. O seu objeto empírico é considerado impossível à luz das ciências sociais convencionais, pelo que a sua simples formulação representa já uma ruptura com eles. O objetivo da sociologia das ausências é transformar objetos impossíveis em possíveis e com base neles transformar as ausências em presenças. (SANTOS, 2006b, p. 102).

Ora, de acordo com esta definição, se a razão metonímica contrai o presente, a sociologia das ausências propóe em contrapartida a expansão do presente. É por meio da expansão do presente, para incluir nele mais experiência, que a sociologia das ausências combate a razão metonímica. 
Se esta última se caracteriza pela produção de ausências, por meio de cinco monoculturas, a sociologia das ausências a ela se opóe por meio de cinco ecologias. Assim, a sociologia das ausências se opóe à monocultura do saber e do rigor científico, com sua ecologia dos saberes; à monocultura do tempo linear, com uma ecologia das temporalidades; à monocultura da naturalização das diferenças, com uma ecologia do reconhecimento; à monocultura da escala dominante, com uma ecologia da transescala; à monocultura do produtivismo, com uma ecologia das produtividades.

Por outro lado, se a razão proléptica "[...] é a face da razão indolente quando concebe o futuro a partir da monocultura do tempo linear", expandindo-o, a sociologia das emergências a ela se opóe contraindo o futuro. Contrair o futuro é uma maneira de prepará-lo, fazendo emergir as pistas, as latências e possibilidades que existem no presente como sinais do futuro. Sinais ou pistas que podem ser promissores indicando o "ainda não", mas sem romantismos. Portanto, conforme sua definição, a sociologia das emergências é o procedimento que "[...] consiste em substituir o vazio do futuro segundo o tempo linear (um vazio que é tudo ou nada) por um futuro de possibilidades plurais e concretas, simultaneamente utópicas e realistas, que vão se constituindo no presente através das actividades de cuidado" (SANTOS, 2006b, p. 115-116).

Por fim, ele afirma ainda que "as duas sociologias estão estreitamente associadas", no intuito de multiplicar e ampliar as experiências presentes, por meio das cinco mencionadas ecologias, e revelar, "por via da multiplicação simbólica das pistas ou sinais”, suas possibilidades futuras, nos diversos campos de atuação, que vão dos conhecimentos às formas de produção, do reconhecimento à democracia, e assim por diante, conforme as referidas ecologias (SANTOS, 2006b, p. 120-121).

Já o terceiro procedimento, conforme dito antes, é o trabalho de tradução. Fundado em uma concepção cosmopolita de razão, este último objetiva lidar com a multiplicação e a diversificação das experiências de forma diferente do que fazem a razão metonímica, com seu conceito restrito de totalidade, e a razão proléptica com a ideia de sentido da história fundada no tempo linear. $\mathrm{O}$ trabalho de traduçáo propóe, por sua vez, novas formas de pensar as totalidades e novos processos de realizar convergências éticas 
e políticas. Assim, com base na razão cosmopolita, o trabalho de tradução pretende responder a dois conjuntos de questóes, que Santos formula nos seguintes termos: primeiro, "como dar conta teoricamente da diversidade inesgotável do mundo? Qual é a alternativa à teoria geral?”; segundo, “[...] se o sentido e a direção da transformação social não estão pré-definidos, o que nos legitima e motiva a agir como se soubéssemos? Qual é o sentido das lutas pela emancipação social?” (SANTOS, 2006b, p. 123).

Para responder ao primeiro grupo de questóes, ele afirma que a alternativa à teoria geral é o trabalho de tradução porque este último procura captar dois momentos - desconstrutivo e reconstrutivo - da relação hegemônica, colonialista. Neste sentido, o trabalho de tradução complementa a sociologia das ausências e a sociologia das emergências, pois objetiva criar inteligibilidade, coerência e articulação em um mundo enriquecido pela multiplicidade e diversidade intelectual, política e emocional. Por isso, ele incide tanto sobre os saberes, recorrendo à hermenêutica diatópica, ${ }^{15}$ quanto sobre as práticas, buscando a inteligibilidade recíproca entre formas de organização e objetivos da ação.

Sobre o segundo conjunto, que pode ser sintetizado pela questão "para que traduzir?”, Santos afirma que o trabalho de traduçáo é o procedimento que nos resta para dar sentido ao mundo. Consiste em um trabalho de imaginação epistemológica e de imaginação democrática que objetiva construir concepções novas e plurais de emancipação social. Seu objetivo é, pois, criar constelaçóes de saberes e de práticas suficientemente fortes e plausíveis para fornecer alternativas ao capitalismo global, cujo sentido é sujeitar a totalidade inesgotável do mundo à lógica mercantil. Daí que a razão cosmopolita prefira imaginar o mundo melhor a partir do presente. Por isso, propóe dilatar o presente e contrair o futuro. Dilatando o campo das experiências, é possível avaliar melhor as alternativas que são hoje possíveis. A diversificação das experiências visa a realizar a tensão entre

15 Para Santos, a hermenêutica diatópica consiste na interpretação de duas ou mais culturas incompletas por meio de um universalismo negativo, entendido como uma teoria geral residual que ele define como uma espécie de "teoria geral sobre a impossibilidade de uma teoria geral". Esta perspectiva, que faz lembrar a ideia de autolimitação, é, para ele, um pressuposto do trabalho de tradução. 
experiências e expectativas ${ }^{16}$; mas, de modo tal que aconteçam no presente, pois hoje e não amanhã é possível viver melhor. Nesse sentido, a imaginação epistemológica e a imaginação democrática implicam justiça cognitiva global e justiça social global (SANTOS, 2006b, p. 122-135).

Conforme prometido na introdução e considerando o que foi mostrado até aqui, a seguir, pretendo lidar com a abordagem que Santos faz da relação entre reconhecimento e redistribuição.

\section{III}

Antes de voltar propriamente ao debate sobre reconhecimento e redistribuição, é preciso, porém, ressaltar que nos textos onde Santos aborda diretamente esses temas, principalmente o do reconhecimento, ele não menciona nenhum dos autores que até o momento têm sido considerados os principais protagonistas desse debate, casos de Nancy Fraser, Axel Honneth (debate reconhecimento/redistribuição), ou mesmo Charles Taylor, em relação mais especificamente ao tema do reconhecimento. ${ }^{17}$ Em outro de seus textos, ele faz referência a Fraser, mas em relação à contribuição teórica dela para o movimento feminista (SANTOS, 2000). Quanto a Honneth e a Taylor - cujas concepçóes de reconhecimento partem da formulação hegeliana -, devemos nos contentar com a ideia de que são alvos indiretos das críticas de Santos, já que, nas duas versóes do texto onde ele trata mais diretamente do tema (SANTOS, 2001, 2006a), Hegel é um dos principais alvos de sua crítica ao pensamento eurocêntrico, conforme se viu no item I.

Por outro lado, no debate entre Fraser e Honneth, vemos em ambos que a preocupação em definir o que cada um entende por reconhecimento é central em seus argumentos. A propósito, Honneth postula o reconhecimento como uma categoria moral abrangente que visa à formação de uma personalidade intacta dos indivíduos no processo de socialização (HONNETH, 2003); Fraser (2002), por sua vez, propóe um conceito de

16 A referida tensão entre experiências e expectativas, que existiu durante muito tempo, foi eliminada, segundo Santos, pela hegemonia neoliberal e consequentemente pela emergência do fascismo social.

17 Ver a propósito: Neves, 2005; Mattos, 2006; Thompson, 2006; Souza, 2010; Bressiani, 2011; Maciel, Rosenfield e Schneider, 2017. 
reconhecimento como status, de inspiração weberiana, que procura se diferenciar do reconhecimento como identidade, que ela atribui a Honneth. Entretanto, não é possível afirmar o mesmo de Santos, que não parece muito preocupado em oferecer um conceito próprio de reconhecimento, embora em suas análises seja clara a relação deste último tema com o problema das identidades, aproximando-se, portanto, das definiçóes que partem de Hegel (SANTOS, 2001, 2006a; 2006c; SANTOS; NUNES, 2003). Assim, tem-se a impressão de que sua concepção de reconhecimento é também tributária da formulação hegeliana, da qual ele se apropria criticamente a partir de uma visão centrada em uma epistemologia do sul, influenciada, em seu caso, tanto por vertentes do pensamento pós-colonial latino americano, exemplificados por autores como Aníbal Quijano (2005) e Enrique Dussel (2005), quanto por autores como Blaise Pascal e Nicolau de Cusa que Santos considera fazerem parte de tradiçóes marginalizadas do pensamento europeu (SANTOS, 2010a, 2010b).

Ainda com relação ao debate sobre reconhecimento e redistribuição, percebe-se que Nancy Fraser e Axel Honneth estão de acordo em abordar o problema em conexáo com uma crítica abrangente do capitalismo com base nos diagnósticos de época que cada um elabora a partir de seus respectivos modelos de teoria crítica (FRASER; HONNETH, 2003, p. 1-7). ${ }^{18}$ O mesmo pode-se dizer de Boaventura de Sousa Santos, que da mesma forma faz seu próprio diagnóstico de época, empregando, para tanto, a exemplo de Honneth, um procedimento reconstrutivo. Ele faz também, como os outros dois, uma crítica abrangente do capitalismo.

Entretanto, sua abordagem da relação entre reconhecimento e redistribuição, que remete diretamente ao par igualdade/diferença conforme se pode ver no trecho citado a seguir, procura, diferentemente de Honneth e Fraser, realçar sua crítica ao eurocentrismo:

As tensões entre a diferença e a igualdade, entre a exigência de reconhecimento da diferença e de redistribuição [...] estão no centro das lutas de movimentos e iniciativas emancipatórias que, contra as reduções eurocêntricas dos termos fundamentais (cultura, justiça, direitos,

18 As divergências entre ambos a esse respeito surgem apenas em decorrência das diferentes concepções de teoria crítica que cada um deles sustenta e sobre as quais já escrevi alhures (SILVA, 2008, p. 93-I I0). 
cidadania), procuram propor noções mais inclusivas e, simultaneamente, respeitadoras da diferença de concepções alternativas da dignidade humana. (SANTOS; NUNES, 2003).

Assim, em um texto mais diretamente dedicado aos temas da igualdade e da diferença (SANTOS, 2006c), e que será minha principal referência neste item, ele defende a ideia dinâmica de uma "construção intercultural", na qual a resolução da tensão entre as duas categorias em favor da prioridade a uma ou outra dependerá das condições específicas em que o problema se apresente. Aqui, conforme se verá a seguir, seu diagnóstico da modernidade ocidental é crucial para a emergência da contradição entre termos que ele considera complementares.

Santos (2006c, p. 279) inicia sua análise da relação entre os dois temas afirmando que "[...] a desigualdade e a exclusão têm na modernidade ocidental um significado totalmente diferente do que tiveram nas sociedades do antigo regime". Isto porque desde o advento da modernidade ocidental termos como igualdade, liberdade e cidadania são "reconhecidos como princípios emancipatórios da vida social”. Nesse novo contexto, acrescenta ele, "[...] a igualdade e a exclusão têm, pois, de ser justificadas como excepçóes ou incidentes de um processo societal que lhes não reconhece legitimidade, em princípio. E, perante elas, a única política social legítima é a que define os meios para minimizar uma e outra". No entanto, Santos sustenta que isso não "vale para as sociedades sujeitas ao colonialismo europeu", porque nestas últimas "[...] vigoraram a desigualdade e a exclusão como princípio de regulação cuja validade não implicou qualquer relação dialética com a emancipação"; portanto, a elas restou "quando muito" a opção "entre a violência da coerção e a violência da assimilação". Trata-se, pois, de uma trajetória de "fracasso que se desenrolou como se o colonialismo náo fosse um factor", cuja análise, ele salienta, "escapou" até mesmo "aos críticos mais acérrimos desse fracasso". ${ }^{19}$ Por isso, afirma ele, cabe à perspectiva pós-colonial "mostrar que o 'outro' da modernidade europeia, a 'exterioridade colonial', foi, de facto, um elemento constitutivo originário da modernidade e que a sua exclusão do círculo da dialéctica regulação/emancipação codeterminou o fracasso desta no âmbito em que foi confinada, as sociedades europeias.

19 Sobre a omissão da teoria crítica europeia em relação ao colonialismo, alegada por Santos, ver também: Silva, $2018 a$. 
Para Santos (2006c, p. 280):

A desigualdade e a exclusão são dois sistemas de pertença hierarquizada. No sistema de desigualdade, a pertença dá-se pela integração subordinada enquanto que no sistema de exclusão a pertença dá-se pela exclusão. A desigualdade implica um sistema hierárquico de integração social. Quem está em baixo está dentro e a sua presença é indispensável. Ao contrário, a exclusão assenta num sistema igualmente hierárquico mas dominado pelo princípio da segregação: pertence-se pela forma como se é excluído. Quem está em baixo, está fora. Estes dois sistemas de hierarquização social, assim formulados, são tipos ideais, pois que, na prática, os grupos sociais inserem-se simultaneamente nos dois sistemas, em combinações complexas.

Ademais, Santos considera que Karl Marx e Michel Foucault são os principais teóricos, respectivamente, da desigualdade e da exclusão. Marx, afirma ele, foi "o grande teorizador da desigualdade na modernidade capitalista", enquanto Foucault foi "o grande teorizador da exclusão". A teoria de Marx, centrada na análise da relação capital/trabalho - "o grande princípio da integraçáo social na sociedade capitalista", aborda a desigualdade entre capitalistas e trabalhadores, entendida como exploração classista. A análise de Foucault, por outro lado, diferente da de Marx que prioriza a desigualdade de classe como fenômeno socioeconômico, lida com a exclusão a partir de uma perspectiva cultural e social, tratando-a como um "fenômeno de civilização" (SANTOS, 2006c, p. 280-281).

Para Santos, esses dois sistemas de hierarquização são, na verdade, tidos como tipos ideais. É preciso lembrar, afirma ele, que há duas outras formas de hierarquização presentes na modernidade capitalista; e algumas delas, como o racismo e o sexismo, são híbridas em relação aos sistemas de desigualdade e de exclusão. Por isso, ele especifica:

No caso do racismo, o princípio da exclusão assenta na hierarquia das raças e a integração desigual ocorre, primeiro, através da exploração colonial (escravatura, trabalho forçado), e depois, através da imigração. No caso do sexismo, o princípio da exclusão assenta na distinção entre o espaço público e o espaço privado e o princípio da integração desigual, no papel da mulher na reprodução da força de trabalho no seio da família e, mais tarde, tal como o racismo, pela integração em formas desvalorizadas de força de trabalho. [...] O racismo e o sexismo são, pois, dispositivos de hierarquização que combinam a desigualdade de Marx e a exclusão de Foucault. (SANTOS, 2006c, p. 28I). 
Entretanto, Santos acrescenta que os sistemas da desigualdade e da diferença fundam-se, paradoxalmente, em fundamentalismos, uma vez que o primeiro se baseia no essencialismo da igualdade, que justifica o contrato de trabalho como "um contrato entre partes livres e iguais", enquanto o segundo funda-se no essencialismo da diferença, legitimado pela "cientifização da normalidade" e, pelo "determinismo biológico da desigualdade racial e sexual". Além do mais, ele lembra, "um sistema de desigualdade pode estar, no limite, acoplado a um sistema de exclusão", em diferentes graus. E completa, por fim, que o extremo da exclusão é o extermínio e o extremo da desigualdade é a escravatura (SANTOS, 2006c, p. 281-282). ${ }^{20}$ Mas, para evitar essas situaçóes extremas, a regulação social capitalista dispóe de "mecanismos que permitem controlar ou manter dentro de certos limites esses processos"; ao mesmo tempo, porém, ela reduz as "possibilidades de emancipação às que são possíveis na vigência do capitalismo” (SANTOS, 2006c, p. 282).

Santos (2006c) afirma, no entanto, que hoje esse tipo de gestão da desigualdade e da exclusão está em crise. No sistema de desigualdade, a crise se manifesta pela crise do Estado de bem-estar, cuja política de integração social, assentava-se no trabalho e no consumo. ${ }^{21}$ A crise do Estado de bem-estar, motivada pelas transformaçóes do capitalismo associadas com a globalização da economia e com a ascensão do neoliberalismo, teve consequência direta para a política de pleno-emprego e a política fiscal redistributiva que fundamentavam o pacto socialdemocrata, gerando uma situação de precariedade das condiçóes de vida que se traduz na ascensão do darwinismo social e no esvaziamento do conceito de cidadania, até mesmo nos países do centro.

Mas a crise não se limitou ao chamado sistema de desigualdade, pois a "globalização da cultura, tal como a da economia, é um processo muito desigual e contraditório” (SANTOS, 2006c, p. 300). Assim, embora se

20 Ver também a respeito o artigo "Civil Citizenship against Social Citizenship?" (FRASER; GORDON, 1994).

21 Tratava-se, na verdade, segundo Santos, de um pacto socialdemocrata, no qual: "Os trabalhadores organizados no movimento operário, renunciam às suas reivindicações mais radicais, as da eliminação do capitalismo $e$ da construção do socialismo, e os patrões renunciam a alguns dos seus lucros, aceitando ser tributados com o fim de promover uma distribuição mínima da riqueza e de conseguir alguma proteção social e segurança social para as classes trabalhadoras" (SANTOS, 2006c, p. 286). 
"De que lado estás, Ariel?": reconhecimento e redistribuição na teoria da emancipação de Boaventura de Sousa Santos | Josué Pereira da Silva

distinga da economia, a globalização da cultura acabou por misturar exclusão e desigualdade, metamorfoseando os dois sistemas. ${ }^{22}$

Santos afirma, no entanto, que, a despeito de tudo isso, "os sistemas de desigualdade e de exclusão não são o deus ex-machina da modernidade capitalista", uma vez que sua constituição, consolidação e metamorfoses

[...] ocorrem num campo de relações sociais conflituais, onde intervêm grupos sociais constituídos em função da classe, do sexo, da raça, da etnia, da religião, da região, da cidade, da língua, do capital escolar, cultural ou simbólico, do grau de desvio face aos critérios hegemônicos de normalidade e de legalidade. (SANTOS, 2006c, p. 312).

E, ainda que cada um desses grupos tenha seu próprio critério de pertença aos sistemas de desigualdade e de exclusão, não dá para se estabelecer em abstrato uma hierarquia entre eles. ${ }^{23}$

Por outro lado, embora considere a dificuldade de se articular políticas de igualdade e políticas de exclusão em razão da diversidade de critérios de pertencimento dos diferentes movimentos sociais, Santos acredita que é possível superá-la partindo-se do seguinte imperativo intercultural: "[...] temos o direito a ser iguais sempre que a diferença nos inferioriza; temos o direito de ser diferentes sempre que a igualdade nos descaracteriza" (SANTOS, 2006c, p. 313). Este imperativo torna-se, assim, a base para se buscar um consenso mínimo como "[...] a primeira condição de uma luta utópica mas realista contra a acrescida virulência dos sistemas de desigualdade e de exclusão" (SANTOS, 2006c, p. 315).

Retornando à metáfora de Nuestra América, Santos afirma que é preciso indagar se ela tem, "[...] condiçóes para continuar a simbolizar uma

22 Isso se torna evidente, segundo Santos, "[...] à luz de novos fenômenos de pertença subordinada em que se misturam cada vez mais intrincadamente a pertença pela integração e a pertença pela exclusão com repercussões significativas na composição social dos grupos sociais neles envolvidos e nas lutas sociais que eles protagonizam" (SANTOS, 2006c, p. 301-302), exemplificados pelas lutas em torno da biodiversidade e do espaço eletrônico. Ambos - biodiversidade e ciberespaço - são vistos por ele como arenas de luta importantes "na construção do cosmopolitismo subalterno e insurgente" (SANTOS, 2006c, p. 308).

23 Por isso, ele adiciona: "[...] pode dizer-se, no entanto, que no sistema da desigualdade (e principalmente no contexto dos países centrais e semiperiféricos) o factor classe tem tido um papel preponderante e continua a tê-lo ainda que crescentemente a sua eficácia discriminadora dependa de outros factores nomeadamente da raça, da etnia e do sexo. Pelo contrário, no sistema de exclusão têm preponderado estes e outros factores de discriminação, cabendo à classe uma eficácia apenas complementar, potenciadora ou atenuadora da discriminação constituida pelos outros factores" (SANTOS, 2006c, p. 312). 
vontade utópica de emancipação e de globalização contra-hegemônica, baseada na implicação mútua da igualdade e da diferença”. Sua resposta para a indagação é positiva, mas sob a condição de que Nuestra América seja "[...] desterritorializada e convertida na metáfora da luta das vítimas da globalização hegemônica, onde quer que se encontrem, no Norte ou no Sul, no Oriente ou no Ocidente". Isso porque, segundo ele, ao "[...] revisitarmos as ideias fundadoras de Nuestra América, verificamos que as transformaçóes das últimas décadas criaram as condiçóes para que, hoje, essas ideias possam ocorrer e florescer noutras partes do mundo" (SANTOS, 2006a, p. 216). Entre as razóes que ele dá para tanto, estão: o aumento das interações transfronteiriças, a reemergência do racismo no Norte global, a exigência de se produzir ou sustentar um conhecimento situado e contextualizado e, por fim, a maior proximidade das "entranhas do monstro" como efeito da globalização hegemônica. Nessas circunstâncias, afirma ele, “[...] a nova Nuestra América tem hoje condiçóes para ela própria se globalizar e, desse modo, propor novas alianças emancipatórias com a velha Nuestra América localizada desde há muito”. Assim, continua ele, “[...] a natureza contra-hegemônica de Nuestra América reside na sua capacidade de desenvolver uma cultura política transnacional progressista" (SANTOS, 2006a, p. 217). Para tanto, porém, ele acrescenta, ela deverá concentrar-se nas seguintes tarefas:

[...] identificar as múltiplas articulações locais/globais entre lutas, movimentos e iniciativas; promover os embates entre, por um lado, as tendências e pressões da globalização hegemônica e, por outro, as coligações transnacionais capazes de lhes oferecer resistência, abrindo assim possibilidades para as globalizações contra-hegemônicas; promover a auto-reflexividade interna e externa de modo a que as formas de redistribuição e de reconhecimento, estabelecidas no seio dos movimentos, reflitam as formas de redistribuição e de reconhecimento que as políticas emancipatórias transnacionais desejam ver implementadas no mundo. (SANTOS, 2006a, p. 237).

Essas tarefas, segundo Santos, serão viabilizadas por meio de "novos manifestos". Mas estes últimos serão diferentes do Manifesto Comunista, de Marx e Engels, que a despeito de seu diagnóstico do capitalismo continuar em grande medida atual, é, segundo Santos, um "documento eurocêntrico", que, além disso, errou em muitas de suas previsóes, principalmente na centralidade que atribuiu à classe operária na luta por emancipação. 
Santos se refere, então, aos cinco novos manifestos que correspondem a cinco temas, que ele enumera a seguir sem qualquer ordem de precedência: democracia participativa; sistemas de produçáo alternativos; multiculturalismo, justiças e cidadanias emancipatórias; biodiversidade, conhecimentos rivais e direitos de propriedade intelectual; novo internacionalismo operário. ${ }^{24}$

Santos mobiliza o tema da democracia participativa não para substituir a democracia representativa ou formal, mas para enriquecer esta última, uma vez que para ele a combinação das duas formas de democracia e a correção mútua de ambas deverá contribuir para criar uma democracia de alta intensidade.

Da mesma forma, os sistemas de produção alternativos, que para ele se estendem da economia solidária ao cooperativismo e da economia de subsistência à troca direta, propóem-se como alternativa e desafio ao monopólio da economia de mercado, cuja tendência é mercantilizar o conjunto das relaçôes sociais, já que ele considera normal e até desejável uma sociedade com mercado, mas náo uma sociedade de mercado, como quer o neoliberalismo. Isto porque sua consolidação leva, conforme testemunhamos atualmente, à emergência do fascismo social (SANTOS, 2006d, p. 317-340).

O terceiro manifesto diz respeito ao tema multiculturalismo, justiças e cidadanias emancipatórias e tem como substrato a ideia geral de que a "dignidade humana pode ser formulada em diferentes 'linguagens'”. Para Santos (2006a, p. 220), considerando que a construção das naçóes modernas "[...] foi realizada, na maior parte dos casos, através do esmagamento da identidade cultural e nacional de minorias (e por vezes, mesmo de maiorias), o reconhecimento do multiculturalismo e da multinacionalidade transporta consigo a aspiração à autodeterminação", o que, para se

24 Sobre cada um desses temas - que, aliás, não deixam de ter relação com as cinco ecologias referidas no item II, acima - ele organizou um liuro que conta com contribuições de estudiosos de diversos países e continentes (SANTOS, 2002a, 2002b, 2003, 2005a, 2005b, 2005c). Ao afirmar que há relação entre os novos manifestos e as referidas ecologias, quero afirmar que tal relação não é apenas nas temáticas, mas também no procedimento, porque cada um dos temas objetiva contrapor-se à lógica dominante em seu respectivo espaçotempo, para usar uma expressão do próprio Boaventura de Sousa Santos. 
efetivar, exige "formas alternativas de direito e de justiça e de novos regimes de cidadania". Assim, conclui ele, “[...] o conceito de 'cidadania multicultural' é o lugar privilegiado para fundamentar o tipo de implicação mútua da redistribuição e do reconhecimento" (SANTOS, 2006a, p. 221).

Sobre o tema do quarto manifesto, ele afirma que "a biodiversidade é um dos 'recursos naturais' mais preciosos e mais procurados"; então, pelo fato de estar concentrada nos países do Sul global, a disputa em torno dela sugere clivagens entre Norte e Sul com profundas implicaçóes epistemológicas, já que nesse âmbito "o choque entre conhecimentos rivais é mais evidente” (SANTOS, 2006a, p. 221-222).

O quinto manifesto refere-se ao novo internacionalismo operário, cujas articulações, ainda precárias, em resposta à globalização hegemônica, serão "[...] fundamentais para transformar a política da igualdade, que dominou o velho internacionalismo operário, em uma nova constelação política e cultural, da igualdade e do reconhecimento da diferença” (SANTOS, 2006a, p. 222).

Santos também afirma que nenhum desses cinco temas poderá sozinho "contribuir com êxito para a globalização contra-hegemônica"; mas, o sucesso de tal empreitada tornar-se-á factível se eles forem tomados em conjunto pelos movimentos e iniciativas, em suas articulaçóes e redes como ocorre, por exemplo, no Fórum Social Mundial (SANTOS, 2005, 2006e, p. 399-431).

Ele sugere, ainda, que o fato desses cinco temas terem raízes profundas na América Latina justifica "a expansão simbólica da ideia de Nuestra América”; tal expansão, no entanto, ele acrescenta,

[...] deve ir mais além e incluir a metáfora mais negligenciada no mito de Nuestra América:

Ariel, o espírito do ar na peça $A$ Tempestade, de Shakespeare. Como Caliban, Ariel é o escravo de Próspero. Contudo, para além de não ser deformado como Caliban, recebe um tratamento muito melhor por parte de Próspero, que lhe promete a liberdade se ele o servir fielmente. Como mostrei, a Nuestra América viu-se predominantemente a si própria como Caliban em luta constante e desigual contra Próspero. (SANTOS, 2006a, p. 223).

Em relação à "figura ambígua de Ariel”, mito cujas diversas interpretaçóes pregressas ele também comenta, Santos afirma que chegou a hora de 
dar a ele "[...] uma nova identificação simbólica e de averiguarmos que uso pode ele ter para a promoção do ideal emancipatório de Nuestra América".

Mas, para tanto, ele continua, "é necessário submetê-lo [...] a três transfiguraçôes", conforme descritas a seguir: primeiramente, Ariel "é o mulato de Césaire”; ${ }^{25}$ em segundo lugar, "Ariel é o intelectual de Gramsci”; por fim, "enquanto mulato e intelectual orgânico, Ariel é uma figura de intermediação". No primeiro caso, "[...] o Ariel mulato é a metáfora de uma síntese possível entre a reivindicação do reconhecimento da diferença e a reivindicação da igualdade". No segundo, Ariel, como "intelectual treinado na universidade de Martî", deve estar "inequivocamente, do lado de Caliban, do lado de todos os povos e grupos oprimidos do mundo". E, no terceiro, Ariel é referido a países - Brasil, México, Índia e África do Sul - que ocupam posiçóes intermediárias entre centro e periferia e que, em vez de usarem seu peso econômico e populacional e se unirem para "abrir espaço para a igualdade republicana”, optaram por se unir equivocadamente às naçóes canibalescas com o objetivo de "adquirir tratamento privilegiado por parte de Próspero"; agem, assim, "isoladamente para maximizarem suas próprias possibilidades de sucesso" (SANTOS, 2006a, p. 224-225). Mas, conclui Santos:

A capacidade de os indivíduos e grupos sociais se empenharem em políticas emancipatórias com vista à construção de uma globalização contra-hegemônica, depende da disponibilidade para se assumirem como Caliban, tal como Nuestra América, ou se transfigurarem a si mesmos num Ariel inequivocamente solidário com Caliban. Nessa transfiguração simbólica reside a tarefa mais importante das próximas décadas. (SANTOS, 2006a, p. 225).

Ao que tudo indica, embora Boaventura de Sousa Santos associe os países mencionados acima, assim como Portugal, seu país de origem, ao mito de Ariel, ele próprio parece, pela posição que ocupa nos debates, também reivindicar para si esse lugar de um Ariel transfigurado, à maneira de um intelectual orgânico gramsciano (GRAMSCI, 1971).

A propósito, em um de seus textos mais recentes, Santos propóe três "palavras-guias" que ele considera fundamentais para conduzir a luta das esquerdas: democratizar, desmercantilizar e descolonizar. Elas consistem,

25 Ver Césaire, 1969. Lembro, ademais, que o mulato como figura de mediação remete mais uma vez a Gilberto Freyre, já referido em nota de rodapé anterior. 
na verdade, em estratégicas teóricas e políticas que fundamentam sua crítica do capitalismo, além de também contemplarem o conjunto de temas gerais referidos no que ele denomina cinco novos manifestos (SANTOS, 2016, p. 172-212).

Nestas consideraçóes finais, eu tomo essas três estratégias de Santos como um modelo teórico crítico sintético que me permitirá interpelar criticamente a abordagem dele sobre a relação entre reconhecimento e redistribuição. Além disso, também farei algumas comparações de sua abordagem com as de Axel Honneth e de Nancy Fraser sobre o mesmo tema, realçando possíveis semelhanças e/ou diferenças entre a proposição de Santos e as dos dois outros mencionados autores. Começo, então, pelas comparações entre as abordagens, que serão apenas pontuais. Não me estenderei nas comparaçóes por razão de espaço e também porque já escrevi a respeito em outros lugares. ${ }^{26}$

Santos considera que a democracia foi apropriada por poderes antidemocráticos; por isso, ele fala em "democratizar a própria democracia”. Para tanto, ele afirma ser necessário "tornar evidente que uma decisão democraticamente tomada não pode ser destruída no dia seguinte por uma agência de rating nem por uma baixa cotação nas bolsas" (SANTOS, 2016, p. 180). Em sua noção de democracia de alta intensidade, baseada em uma combinação de democracia representativa e democracia participativa, esse tipo de situação não deveria ocorrer uma vez que decisóes de grande relevância para o conjunto da população náo poderiam ser tomadas apenas de cima para baixo, sem a participação democrática dos atingidos, por agências que no mais das vezes funcionam como corporaçóes de interesses dos poderes econômicos e políticos dominantes. A despeito das diferenças nas terminologias e, mesmo em nuances mais substantivas, sua a noção de democracia de alta intensidade náo conflita com as concepçóes de democracia como cooperaçáo reflexiva de Honneth, ${ }^{27}$ tampouco com a ideia

26 Para uma comparação mais desenvolvida entre as abordagens de Santos e as de Honneth e de Fraser, ver: Silva, 2009, 2017.

27 Conforme o próprio Honneth, a "democracia como cooperação reflexiva" é um modelo que combina "deliberação racional e comunidade democrática" e "encara a ideia normativa de democracia não só como um ideal político, mas principalmente como um ideal social" (HONNETH, 200 I, p. 9I). 
de paridade de participação de Fraser, fundada, a meu ver, na concepção habermasiana de democracia deliberativa (HONNETH, 2001, 2015; FRASER, 2003; SILVA, 2017).

Em relação à segunda "palavra-guia", Santos afirma que "desmercantilizar significa mostrar que usamos, produzimos e trocamos mercadorias, mas que náo somos mercadorias nem aceitamos relacionar-nos com outros e com a natureza como se fossem mercadorias" (SANTOS, 2016, p. 280). Aqui fica clara sua oposição à tendência atual de expansão das relaçóes mercantis promovida pelo neoliberalismo, tendência, aliás, criticada e denunciada por diversos teóricos críticos contemporâneos (GORZ, 1983, 2003; KURZ, 1992; POSTONE, 1993). Decorrem daí, como contrapontos, dois desdobramentos necessários, já contemplados nos novos manifestos: os sistemas alternativos de produção e a questão ecológica, esta também vinculada à biodiversidade. Nesse quesito, a crítica de Santos mostra uma radicalidade bem maior do que as abordagens tanto de Honneth quanto de Fraser, que procuram ambas recuperar a ideia de incrustamento social dos mercados, em linha com a conhecida tese de Karl Polanyi, segundo a qual se deixarmos o mercado agir livre de controle social ele destruirá a sociedade (POLANYI, 1944). Isso não quer dizer, no entanto, que Honneth e Fraser não sejam críticos da atual predominância das relaçóes de mercado; significa apenas que a crítica enfática de Santos tem um viés anticapitalista bem mais claro que as dos outros dois (FRASER, 2011; HONNETH, 2015).

É na terceira chave, entretanto, que a abordagem de Santos mais se diferencia das outras. Para Santos, “[...] descolonizar significa erradicar das relaçôes sociais a autorização para dominar outros sob o pretexto de que são inferiores, porque são mulheres, porque têm uma cor de pele diferente ou porque pertencem a uma religião distinta" (SANTOS, 2016, p. 280-281). $\mathrm{Na}$ verdade, afora o fato de o tema do reconhecimento ter por si só implicação para a discussão do colonialismo (FANON, 1952, 2002), o tema da descolonização não aparece, ao menos diretamente, nas formulaçôes de Honneth e de Fraser, a não ser que, no caso da autora norte-americana, a questão de gênero seja tratada como um caso de colonização interna, de certa forma já prevista na definiçáo de Santos citada acima. 
Passo agora, então, às prometidas considerações críticas sobre a abordagem de Santos, exposta nos três itens centrais deste artigo. Inicialmente, conforme mencionei, Santos não se refere aos outros protagonistas do debate objeto deste artigo. Para um autor que tem como chave teórica justamente a crítica do desperdício de experiências pelas teorias eurocêntricas, era de se esperar dele uma interlocução crítica com outros protagonistas do mesmo debate, cujas contribuiçóes podem ser criticadas, mas não ignoradas (SILVA, 2017). Essa é sem dúvida uma lacuna nos textos de Santos que merece ser mencionada.

Considero, em segundo lugar, que ele utiliza de forma acrítica o termo raça e seus derivados (mestiçagem, mulato etc.). Sua posição é no mínimo ambivalente a respeito do emprego desses termos porque, embora se coloque claramente como crítico do eurocentrismo, assim como do racismo decorrente da dominação eurocêntrica, ele simplesmente emprega o termo raça, que é sabidamente uma criação do racismo científico, que objetivava, sobretudo, a construção de um sistema hierárquico de dominação entre povos (AZEVEDO, 2004, 2018; QUIJANO, 2005; GILROY, 2007).

Por outro lado, em terceiro lugar, devo lembrar que Santos não se omite na crítica aos fundamentalismos de diversos tipos, incluindo o dos movimentos sociais (SANTOS, 2007). Entretanto, ao estabelecer uma oposição talvez radical demais (oposição simbólica e não necessariamente geográfica) entre as perspectivas denominadas do Norte e do Sul, ele deixa margem para interpretaçóes maniqueístas, que tomariam partido de um dos lados como se cada um deles fosse puramente bom ou puramente mau. Mas sabemos, obviamente, que a realidade de ambos é bem mais nuançada do que querem algumas teorias e algumas práticas.

Por fim, não é demais lembrar, os temas do reconhecimento e da redistribuição continuam centrais para o debate teórico e político contemporâneo assim como para qualquer projeto voltado à emancipação humana (SILVA, 2018b). Por essa razão, devem fazer parte de uma agenda de luta das esquerdas. 


\section{Referências}

AZEVEDO, C. M. M. de. Anti-racismo e seus paradoxos: reflexôes sobre cota racial, raça e racismo. São Paulo: Annablume, 2004.

AZEVEDO, C. M. M. de. A luta contra o racismo e a questão da identidade negra no Brasil. Contemporânea, v. 8, n. 1, p. 163-191, 2018.

BRESSIANI, N, Redistribuição e Reconhecimento - Nancy Fraser entre Jürgen Habermas e Axel Honneth. Caderno CRH, v. 24, n. 62, p. 331-352, 2001.

BUCK-MORSS, S. Hegel, Haiti, and Universal History. Pittsburgh: University of Pittsburgh Press, 2009.

CÉSAIRE, A. Une Tempête. Paris: Éditions du Seuil, 1969.

DUSSEL, E. Europa, modernidade e eurocentrismo. In: LANDER, E. (Org.). A colonialidade do saber: eurocentrismo e ciências sociais, perspectivas latino-americanas. Buenos Aires: Clacso, 2005. p. 55-70.

FANON, F. Peau Noire, masques blaches. Paris: Éditions du Seuil, 1952.

FANON, F. Les damnés de la terre. Paris: La Découverte, 2002.

FRASER, N. From redistribution to recognition? Dilemmas of Justice in a 'Post-Socialist' Age. New Left Review, v. 212, p. 68-93, 1995.

FRASER, N. Rething recognition. New Left Review, n. 3, p. 107-120, 2000.

FRASER, N. Mercantilização, Proteção Social e Emancipação: as ambivalências do feminismo na crise do capitalismo. Revista Direito, GV-SP, v. 7, n. 2, p. 617-634, 2011.

FRASER, N.; GORDON, L. Civil Citizenship against Social Citizenship?. In: STREENBERGEN, B. V. (Org.), The Condition of Citizenship. London: Sage Publications, 1994. p. 90-107.

FRASER, N.; HONNETH, A. Redistribution or Recognition? A Political-Philosophical Exchange. London: Verso, 2003.

FREYRE, G. Casa-Grande e Senzala. 20. ed. Rio de Janeiro: Livraria José Olympio Editora, 1980. GILROY, P. Entre Campos: naçôes, cultura e o fascínio da raça. São Paulo: Annablume, 2007.

GORZ, A. Les chemins du Paradis: L’agonie du capital. Paris: Galilée, 1983.

GORZ, A. L’immatériel. Connaissance, valeur et capital. Paris: Galilée, 2003.

GRAMSCI, A. Selections from the prison notebooks. New York: International Publishers, 1971.

HEGEL, G. W. F. The Philosophy of History. New York: Dover Publications; INC, 1956.

HEGEL, G. W. F. Phenomenology of Spirit. Oxford: Oxford University Press, 1977. 
HONNETH, A. Democracia como cooperação reflexiva. John Dewey e a teoria democrática hoje. In: SOUZA, J. (Org.). Democracia Hoje. Novos desafios para a teoria democrática contemporânea. Brasília: Editora UnB, 2001. p. 63-91.

HONNETH, A. Luta por Reconhecimento. A gramática moral dos conflitos sociais. São Paulo: Editora 34, 2003.

HONNETH, A. O Direito da Liberdade. São Paulo: Martins Fontes, 2015.

KURZ, R. O colapso da modernização. São Paulo: Paz e Terra, 1992.

MACIEL, F.; ROSENFIELD, C.; SCHNEIDER, É. Reconhecimento, justiça e desigualdade: uma agenda de pesquisa. Revista Brasileira de Sociologia, v. 5, n. 11, p. 271-194, 2017.

MARTÍ, J. Nuestra América. Buenos Aires: Nuestra América Editorial, 2005.

MATTOS, P. A sociologia política do reconhecimento. As contribuições de Charles Taylor, Axel Honneth e Nancy Fraser. São Paulo: Annablume, 2006.

NEVES, P. S. Luta anti-racista: entre reconhecimento e redistribuição. Revista Brasileira de Ciências Sociais, v. 20, n. 59, p. 81-96, 2005.

POLANYI, K. The great transformation. Boston: Beacon Press, 1944.

POSTONE, M. Time, labor, and social domination. New York: Cambridge University Press, 1993.

QUIJANO, A. Colonialidade do poder, eurocentrismo e América Latina. In: LANDER, E. (Org.). A colonialidade do saber: eurocentrismo e ciências sociais, perspectivas latino-americanas. Buenos Aires: Clacso, 2005. p. 227-278.

SANTOS, B. de S. Um discurso sobre as ciências.14. ed. Porto: Ediçóes Afrontamento, 1987.

SANTOS, B. de S. Crítica da razáo indolente: contra o desperdício de experiência. São Paulo: Cortez Editora, 2000.

SANTOS, B. de S. Nuestra America. Reinventing a Subaltern Paradigm of Recognition and Redistribution. Theory, Culture \& Society, v. 18, n. 2-3, p. 185-217, 2001.

SANTOS, B. de S. (Org.). Democratizar a democracia: os caminhos da democracia participativa. Rio de Janeiro: Civilização Brasileira, 2002a.

SANTOS, B. de S. (Org.). Produzir para viver: os caminhos da produçáo não capitalista. Rio de Janeiro: Civilização Brasileira, 2002b.

SANTOS, B de S. (Org.). Reconhecer para libertar: os caminhos do cosmopolitismo multicultural. Rio de Janeiro: Civilização Brasileira, 2003.

SANTOS, B. de S. O Fórum Social Mundial: manual de uso. São Paulo: Cortez Editora, 2005a.

SANTOS, B. de S. Semear outras soluçóes: Os caminhos da biodiversidade e dos conhecimentos rivais. Rio de Janeiro: Civilização Brasileira, 2005b. 
"De que lado estás, Ariel?": reconhecimento e redistribuição na teoria da emancipação de Boaventura de Sousa Santos | Josué Pereira da Silva

SANTOS, B de S. Trabalhar o mundo: os caminhos do novo internacionalismo operário. Rio de Janeiro: Civilização Brasileira, 2005c.

SANTOS, B. de S. Nuestra América. Reinventar um paradigma subalterno de reconhecimento e redistribuição. In: SANTOS, B. de S. A gramática do tempo: para uma nova cultura política. São Paulo: Cortez Editora, 2006a. p. 191-225.

SANTOS, B. de S. Uma sociologia das ausências e uma sociologias das emergências. In: SANTOS, B. de S. A gramática do tempo: para uma nova cultura política. São Paulo: Cortez Editora, 2006b. p. $93-135$.

SANTOS, B. de S. A construção intercultural da igualdade e da diferença. In: SANTOS, B. de S. A gramática do tempo: para uma nova cultura política. São Paulo: Cortez Editora, 2006c. p. 279-316.

SANTOS, B. de S. A crise do contrato social da modernidade e a emergência do fascismo social. In: SANTOS, B. de S. A gramática do tempo: para uma nova cultura política. São Paulo: Cortez Editora, 2006d. p. 317-340.

SANTOS, B. de S. A crítica da governança neoliberal: o Fórum Social Mundial como política e legitimidade subalterna. In: SANTOS, B. de S. A gramática do tempo: para uma nova cultura política. São Paulo: Cortez Editora, 2006e. p. 399-431.

SANTOS, B. de S. Renovar a teoria crítica e reinventar a emancipaçáo social. São Paulo: Boitempo, 2007.

SANTOS, B. de S. (Org.). Para além do pensamento abissal: das linhas globais a uma ecologia de saberes. In: SANTOS, B. de S.; MENEZES, M. P. (Org.). Epistemologias do Sul. São Paulo: Editora Cortez, 2010a. p. 31-83.

SANTOS, B. de S. Um Ocidente não-ocidental? A filosofia à venda, a douta ignorância e a aposta de Pascal. In: SANTOS, B. de S.; MENEZES, M. P. (Org.). Epistemologias do Sul. São Paulo: Editora Cortez, 2010b. p. 519-562.

SANTOS, B. de S. Os processos de globalização. In: SANTOS, B. de S. (Org.). Globalizaçáo e as Ciências Sociais. 4. ed. São Paulo: Cortez Editora, 2011. p. 25-102.

SANTOS, B. de S. A difícil democracia. Reinventar as esquerdas. São Paulo: Boitempo, 2016.

SANTOS, B. de S.; NUNES, J. A. Introdução: para ampliar o cânone do reconhecimento, da diferença e da igualdade. In: SANTOS, B. de S. (Org.). Reconhecer para libertar: os caminhos do cosmopolitismo multicultural. Rio de Janeiro: Civilização Brasileira, 2003. p. 25-68.

SHAKESPEARE, W. The Tempest. New York: New American Library, 1964.

SILVA, J. P. da. Trabalho, cidadania e reconhecimento. São Paulo: Annablume, 2008.

SILVA, J. P. da. Reconhecimento, redistribuição e as ambivalências do discurso sobre o bolsa família. Ciências Sociais Unisinos, v. 45, n. 3, p. 196-205, 2009. 
SILVA, J. P. da. Por que renda básica?. São Paulo: Annablume, 2014.

SILVA, J. P. da. O que é crítico na sociologia crítica?. Revista Brasileira de Ciências Sociais, v. 32, n. 93, p. 1-18, 2017.

SILVA, J. P. da. Epistemologia do Sul como Teoria Crítica? Nota crítica sobre a teoria da emancipação de Boaventura de Sousa Santos. In: CHAGURI, M.; MEDEIROS, M. (Org.). Rumos do Sul. Periferia e pensamento social. São Paulo: Alameda, 2018a. p. 89-108.

SILVA, J. P. da. What is Left? Nota crítica sobre desigualdade e justiça. Caderno CRH, 2018b. (no prelo).

SOUZA, L. G. O estado das coisas no debate entre redistribuição e reconhecimento. Idéias, ano 1, n. 1, p. 183-207, 2010.

SOUZA, L. G. A recepção da teoria do reconhecimento no Brasil. In: SILVA, J. P. da (Org.). Sociologia Crítica no Brasil. São Paulo: Annablume, 2012. p. 213-244.

THOMPSON, S. The Political Theory of Recognition. A critical introduction. Cambridge: Polity Press, 2006.

\section{“Which Side are You On, Ariel?”: Recognition and redistribution in Boaventura de Sousa Santos's theory of emancipation}

\section{Abstract:}

The article deals with Boaventura de Sousa Santos's approach to the debate between recognition and redistribution. Having in mind both José Martís idea of Nuestra America and the Shakespearean metaphor of Ariel, Santos develops what he names subaltern paradigm of recognition (difference) and redistribution (equality), based on an epistemology of the south which he opposes to the socalled European-American paradigm, understood as the neo-liberal globalization. He argues, then, for the need to face this dominant paradigm of globalization with a counter-hegemonic paradigm of globalization.

Keywords: Recognition. Redistribution. Epistemology of the South. Nuestra America. Boaventura de Sousa Santos.

Recebido em 28/09/2018

Aprovado em 26/11/2018 